\title{
Intraepidermal Epithelioma of Jadassohn
}

National Cancer Institute

\section{Source}

National Cancer Institute. Intraepidermal Epithelioma of Jadassohn. NCI Thesaurus. Code C4110.

A rare cutaneous lesion presenting as a scaly verrucous plaque. Morphologically, the plaque contains nests of basaloid cells. 